\title{
Design of Palm Vein Authentication System
}

\author{
Minal Ghute ${ }^{1^{*}}$, Mridula Korde $^{2}$, Kanchan Kamble ${ }^{3}$ and Sachin Khade ${ }^{4}$ \\ ${ }^{1,3,4}$ Yeshwantrao Chavan College of Engineering, Nagpur, India \\ ${ }^{2}$ Shri Ramdeobaba College of Engineering and Management, Nagpur, India
}

\section{ABSTRACT}

Palm vein technology is one among the upcoming technology which is very secure because nobody can copy it. To verify the identification, this palm vein system uses the vein pattern of the palm of human hand. This technique is safer than the other biometric system because it's contactless system and each person has different vein. During this paper Palm vein authentication system is meant using Raspberry Pi single-board computer. Palm vein system consists of vein detection and equalization and thresholding. Comparison of the registered palm vein and input palm vein is completed in few seconds. Palm vein authentication system is predicated on embedded platforms like Raspberry Pi with libraries tenser flow and Open-CV.

KEY WORDS: MATCHING, PALM VEIN, RASPBERRY PI, REGISTERING, THRESHOLDING.

\section{INTRODUCTION}

Palm Vein Authentication is nothing but pattern authentication technology. In this system the human palm vein is employed as biometric feature. Palm veins of every person are different from one another and it exists beneath human skin, hence it's difficult to at least one to repeat it. Palm Vein Authentication System is used to confirm the identification of a specific person. During this system Raspberry PI B+ model used, which is card sized computer [Mr.Shobit, 2014, Gunjan Shah, 2015, K. C. Smith,1981]. In this system images can passes through different sort of process. It uses detection and equalization, thresholding. Finally input image and registered image get compared. Then identification of that person is identified. Raspberry Pi with libraries tenser flow and Open -CV.

\section{ARTICLE INFORMATION}

*Corresponding Author: minal_ghute@rediffmail.com

Received 19th Oct 2020 Accepted after revision 23 rd Dec 2020

Print ISSN: 0974-6455 Online ISSN: 2321-4007 CODEN: BBRCBA

Thomson Reuters ISI Web of Science Clarivate Analytics USA and Crossref Indexed Journal

\section{Clarivate
Analytics}

NAAS Journal Score 2020 (4.31)

A Society of Science and Nature Publication,

Bhopal India 2020. All rights reserved.

Online Contents Available at: http//www.bbrc.in/

Doi: $h t t p: / / d x$.doi.org/10.21786/bbrc/13.14/64
Palm Vein Authentication System is based on the vein patterns which is different for each individual. When user palm is held over a scanner, a near-infrared light maps the things of the veins [J.-C. Lee, 2012, Vicky Ambule,2013, Swati K Jichkar,2016]. The rays are absorbed by the blood cells present within the veins and it maps veins as a black lines, whereas the remaining hand structure shows up as white[Wenxiong Kang and Qiuxia Wu,2014]. Now this vein pattern is compared with the preregistered pattern in order that the individual or peoples are often authenticated. As veins are internal within the body and have a wealth of differentiating features, attempts to forge an identity are extremely difficult, thereby enabling a high level of security [Vicky R Ambule, 2012, Raj Gusain, 2018, Y.Zhou, 2011]. After conducting the literature survey on palm vein recognition techniques, the overall description of Palm Vein Authentication and its corresponding method. A lot of work has already been done on the Palm Vein recognitionThe accuracy and reaction time of the prevailing system is slow which may be improved.

\section{METHODOLOGY}

Working: Palm Vein Authentication Functional block diagram is shown in fig.1, it consists of Raspberry PI B+ model, IR-LEDS, Noir Camera and Power Supply. For

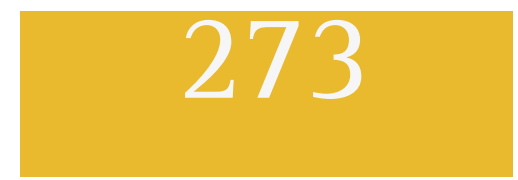


designing purpose Tenser Flow and Open-CV software are used. In this paper Raspberry $\mathrm{B}+$ is used, which is modified version of the original Raspberry $\mathrm{Pi}$. This is nothing but the card sized computer, this device have ability to interact with the outside world and used in wide array of digital maker projects, this is the low cost computer.

The infrared Camera Module v2 (Pi NOIR) replaced the original Pi NOIR Camera Module in April 2016. This noir camera consists of a Sony IMX219 8-megapixel sensor. It is almost similar to regular camera; there is only single difference that it is not consist of infrared filter. According to that pictures that you take at day light it looks curious, but we can see in the dark with infrared lighting. IR LEDs are used.IR LED is nothing but the Infrared light emitting diode. It is a special purpose LED emitting infrared rays ranging from 700nm to $1 \mathrm{~nm}$ wavelengths. This IR LED is usually consisting of gallium arsenide or aluminium gallium arsenide. This IR LED used as sensor in this Palm Vein Authentication System.

Power supply is given with the help of $5 \mathrm{v}$ adaptor and one pin is plug in to PC.There are various steps involved in registering the user through the palm vein is as follows: First the palm pattern is registered in the scanners of the palm vein. The registered palm vein pattern and the private detail of the user is saved.

Figure 1: Block Diagram of Palm Vein Authentication System

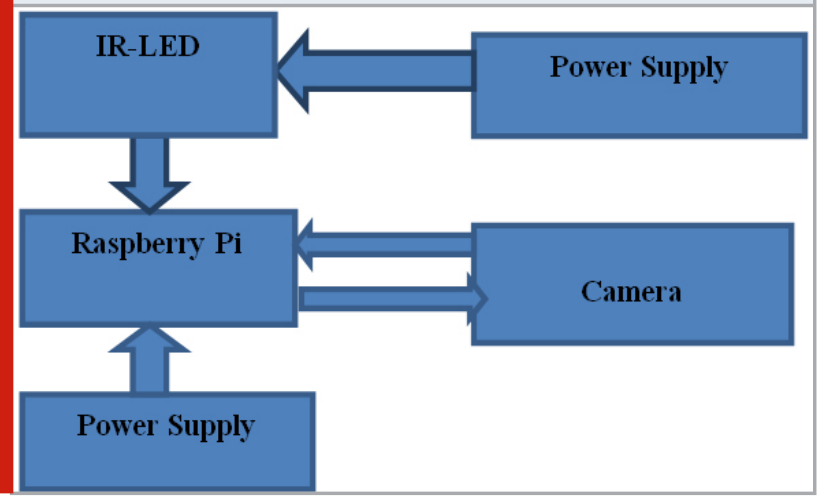

Figure 2: Images of Palm

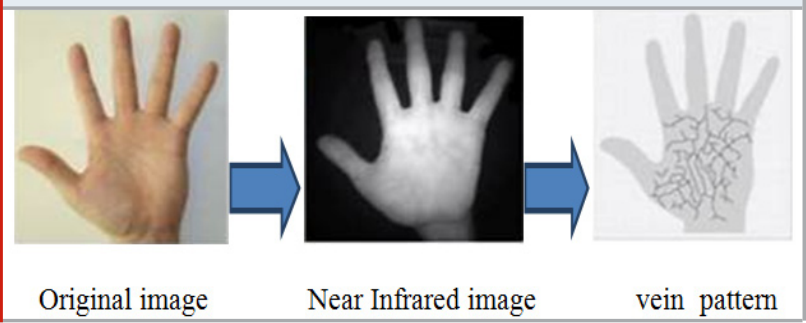

Step 1: In Palm vein authentication technology the Noir camera is used which has high speed and accuracy. It is also easy and simple to use. To read vein pattern simply hold palm a few centimetres over the camera, within a second camera reads user's unique vein pattern. By capturing the vein picture as shown in fig.2, the palm pattern is registered.

Step2: The registered palm pattern is saved into the database with the private details of the client as shown in fig. 3 .

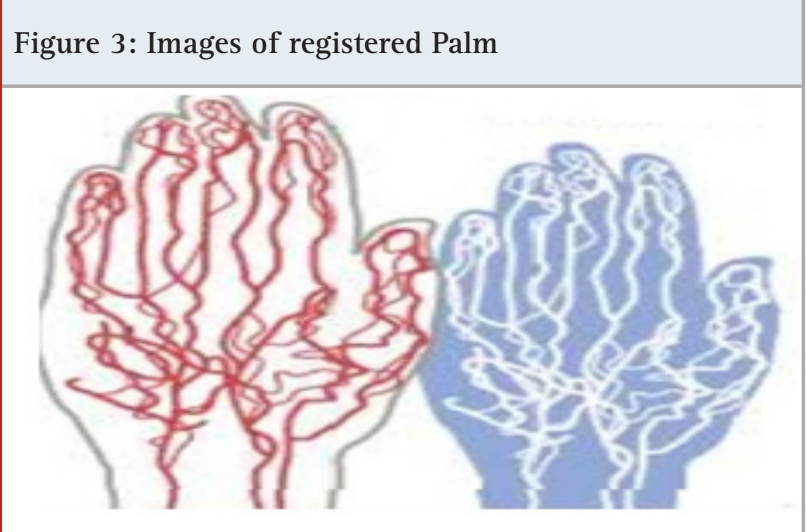

Working of palm vein security system is explained as follows: User must place his/her palm near to scanner as shown in fig.4.After that the scanner/camera use special characteristic of the haemoglobin flowing through the palm vein which absorbs the near-infrared light. Due to which it is possible to get image of what is below the outer skin, something very hard to read or steal. Flowchart is shown in fig.5.After taking image, that image converted into grayscale. In this process colour image get converted into grayscale image.

Figure 4: Palm in front of scanner

In this process remove all colour information, leaving only the luminance of each pixel. While grayscale image get recorded it contain some noise hence then de-noising of the image is done. In this process the image noise get remove or at least get reduce. After de-noising the image, histogram equalization is done. In this process the contrast of the image is improved. It is accomplished by stretching out or distributing the intensity values. After adjusting the contrast of the image, then image inversion is done. After that erosion process is done. In erosion process is one of two fundamental operations in morphological image processing form which other morphological operations are based. 
It is similar to many other kinds of filters like the median filter and Gaussian filter. After that thresholding is done. It is simplest method of segmenting image. Form a grayscale image, thresholding can be used to create binary image. With help of the noir camera the image of palm vein is taken and then it is digitized after that it is encrypted and finally stored as registered palm vein image in the database. Sensors which are connected in the module that is temperature-humidity sensor, gas sensor, dust sensor will monitor the concentration of respective parameter in the underground coal mines. Recorded values of environmental parameters will get displayed on $16^{*} 2$ LCD displays which is programmable.

Figure 5: Flowchart for processing the captured image

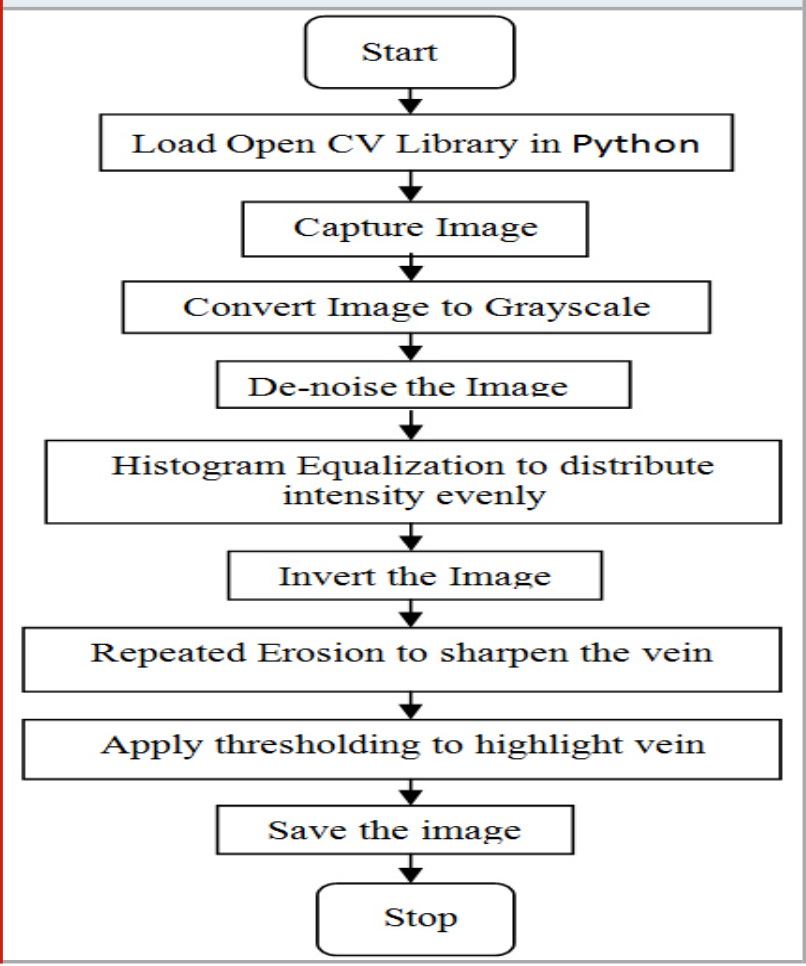

Figure 6: Post crop image of palm

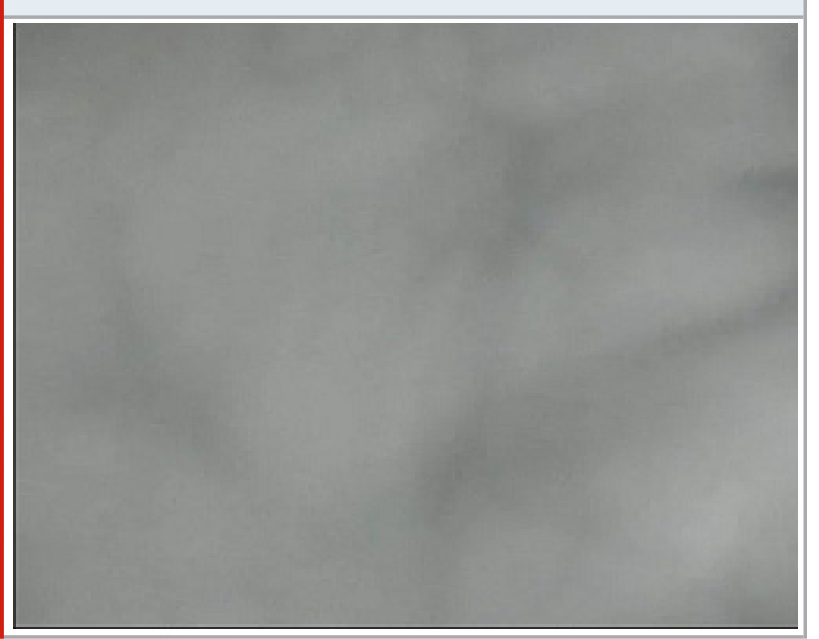

Figure 7: After image denoising

Figure 8: After histogram equalization and inversion

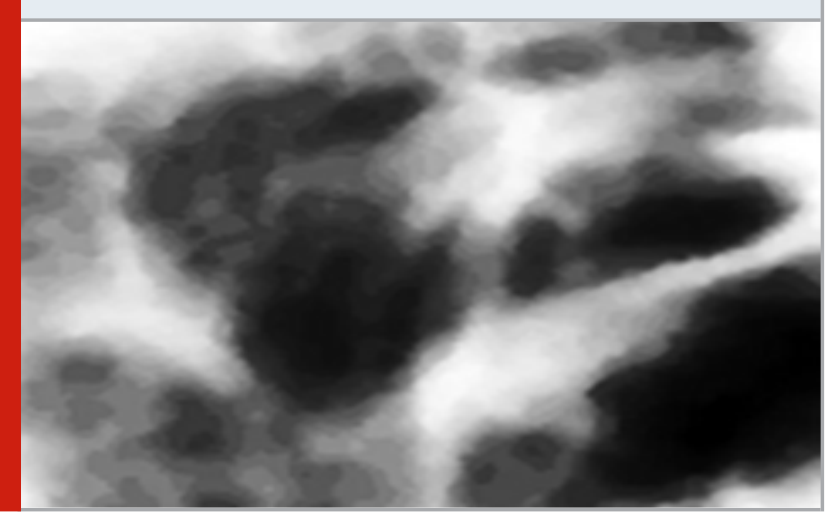

If the concentration of any of the above parameter rises above threshold value then, the alert are going to be given through the buzzer. In case of dust sensor, when the concentration of dust increases in the environment of underground coal mine, the buzzer will get activated and immediately spray pump will start working. Dust sprayer is connected within the module through wired connection. Spray pump is connected to the driving force IC via relay. Relay acts as a switch. On the basis of monitored value of dust sensor, microcontroller will instruct whether to act as open circuit or close circuit. Dust sprayer will settle down the dust in the coal mine. For the safety purpose message will be sent using WSN (wireless sensor network) means using Zigbee module.

\section{RESULTS AND DISCUSSION}

Fig.6 is a cropped image of a palm. Noise is removed in fig.7, which gives smoother image. After that the contrast is increased by using histogram equalization. Then image is inverted as shown in fig.8, in Open CV background of image must be black and foreground is white. The result after Erosion is shown in fig.9.Due to erosion the unwanted outer layers of data in images are striped out. To see how accurate this was, result in fig. 10 is overlaid the vein pattern over the original image as shown in fig. 11 which shows the correlation. 
Figure 9: After skeletonization (repeated erosion)

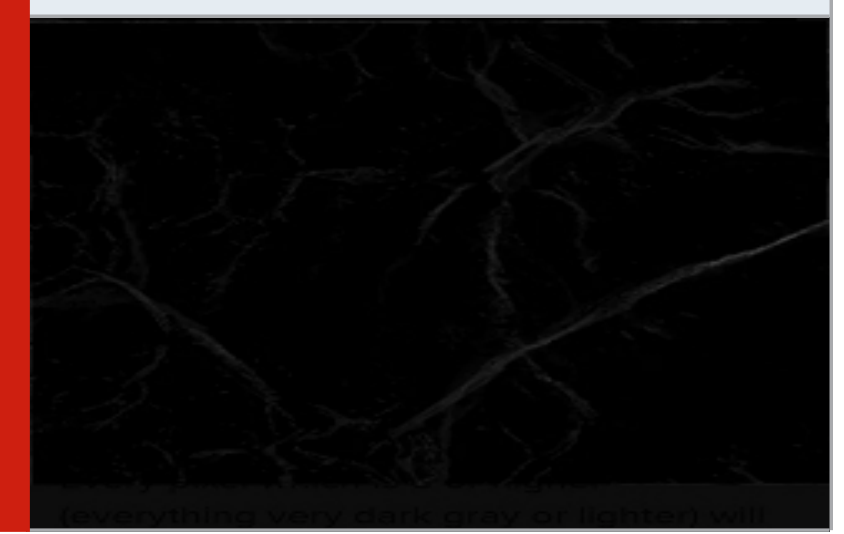

Figure 10: Result after image processing operations

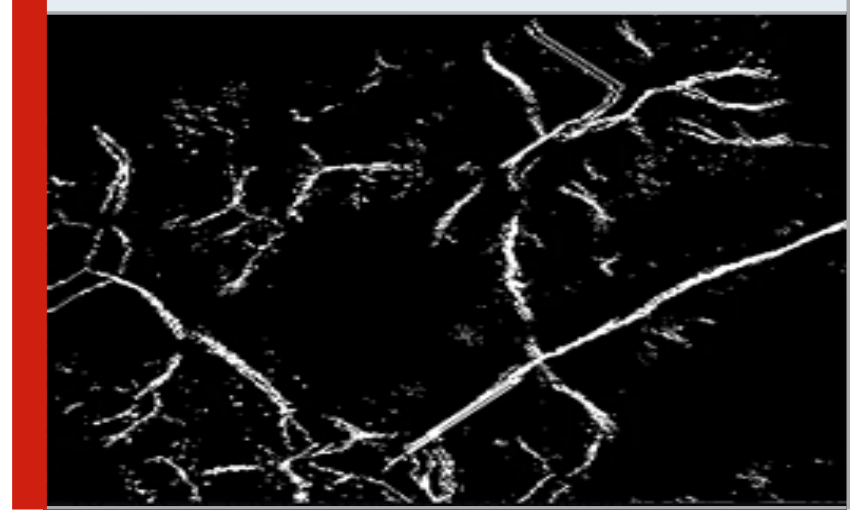

Figure11: Result overlaid on the original image

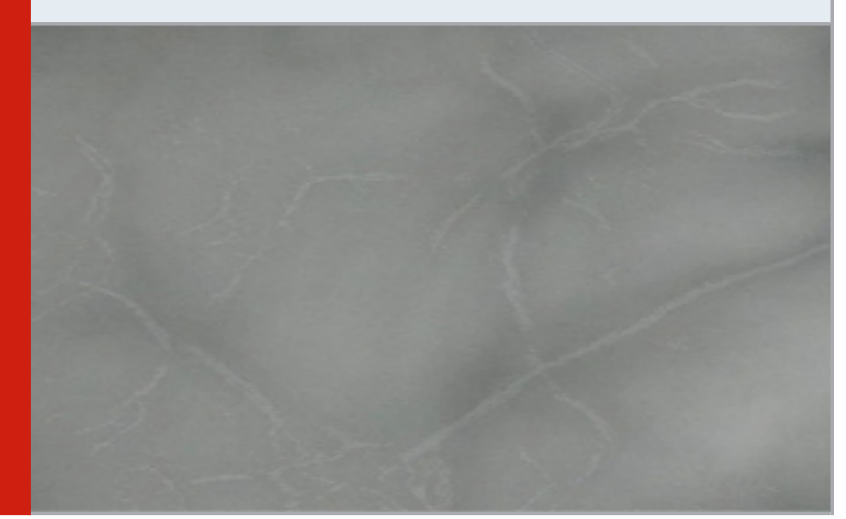

\section{CONCLUSION}

In this paper palm vein authentication system is designed. This technology is highly secure and accurate. The vein pattern in the palm is very much complex and unique to each human being. After comparing the scanned image at that instant of time with save in database if those images are matched then you can entered otherwise again scanned your palm. Palm vein authentication system is highly secured hence it is used in banks, colleges, vertical market, for security purpose, government offices, in passport issuing and in hospitals also. Instead of water Agree Bind is also used which is water based cross linking styrene acrylic environment friendly polymer for dust suppression because it has excellent property to bind with dust particles which will help in dust suppression. In this paper Raspberry Pi having memory 2GB used .If memory increased or use Raspberry Pi with more memory then more data can be saved with all personal detail of user or client.

\section{REFERENCES}

Gunjan Shah,SagarShirke,Sonam Sawant,Yogesh H. Dandawate."Palm vein pattern-based biometric recognition system”, International Journal of Computer Applications in Technology,Vol.51,No.2, DOI: 10.1504/I JCAT.2015.068921,Apr.2015,pp.105-111.

J.-C. Lee, Sep. 2012 A novel biometric system based on palm vein image", Pattern Recognit. Lett., Vol.33, No.12, pp. 1520-1528.

K. C. Smith, "The prospects for multi-valued logic: A technology and applications view," IEEE Transactions on computer, Vol.C-30, No.9, Sep.1981, pp. 619-63.

Mr.Shobit Mishra,Mr.Madhew Oommen, Mr.Sunilkumar, (April 2014) An real time Embedded real time finger vein recognition system", International Journal of Engineering and Teaching Research,Vol.2,Isuue-4, ISSSN:2321-0869.

Raj Gusain, Hemant Jain,Shivendra Pratap, (Feb. 2018) Enhancing bank security using Face Recognition,Iris Scanner and Palm Vein Technology”,3rd International Conference on Internet of Things: Small Innovation and Usages (IoT-SIU), DOI:10.1109/IoT-SIU.2018.8519850, 23-24

Swati K Jichkar, Prof.K P Kamble (2007,0ctober 2016) A Survey on Palm Vein Recognition "International journal of advanced Research in Electrical, Electronics and Instrumentation Engineering (IJAREEIE), Vol.5,Issue 10,ISSN:2278-8875,ISO 3297, pp.7859-7861.

Vicky Ambule, Minal Ghute,Kanchan Kamble,Shilpa Katre,"Adaptive median filter for image enhancement "International journal of Engineering Science and Innovative Technology(IJESIT), Vol.2,Issue 1, ISSN:23195967,IS0 9001:2008 Certified, January 2013,pp.318323.

Vicky R Ambule, MS Ghute,"Performance Analysis of Adaptive Median Filter In Reducing Impulse Noise", International Journal of Research in Computer and Communication Technology (IJRCCT), Vol.1, Issue 5, October 2012,pp. 207-209.

Wenxiong Kang and Qiuxia Wu,"Contactless Palm Vein recognition using a mutual foreground-based local binary pattern,"IEEE Trans.Inf.Forensics Security,Vol.9, No.11, Nov.2014, pp.1974-1985.

Y.Zhou ,A.Kumar,"Human identification using palmvein images” ,IEEE Trans. Inf. Forensics Security, Vol.6, No.4, Dec. 2011, pp. 1259-1274. 